\title{
Photodegradation of sulfapyridine under simulated sunlight irradiation: Kinetics, mechanism and toxicity evolvement
}

\author{
Jian $\mathrm{Xu}^{\mathrm{a}}$, Zhineng Hao ${ }^{\mathrm{a}, \mathrm{b}}$, Changsheng Guo ${ }^{\mathrm{a}}$, Yuan Zhang ${ }^{\mathrm{a}, *}$, Yan $\mathrm{He}^{\mathrm{a}}$, Wei Meng ${ }^{\mathrm{a}}$ \\ ${ }^{a}$ State Key Laboratory of Environmental Criteria and Risk Assessment, Chinese Research Academy of Environmental Sciences, Beijing 100012, China \\ ${ }^{\mathrm{b}}$ State Key Laboratory of Environmental Chemistry and Ecotoxicology, Research Center for Eco-Environmental Sciences, Chinese Academy of Sciences, Beijing 100085, China
}

\section{H I G H L I G H T S}

- Sulfapyridine was effectively photodegraded under UV-vis irradiation.

- Factors affecting the photodegradation process were investigated.

- Degradation intermediates were identified and possible pathway was proposed.

- Bioassay test showed reaction products were much more toxic than parent compound.

\section{A R T I C L E I N F O}

\section{Article history:}

Received 16 August 2013

Received in revised form 13 October 2013

Accepted 14 October 2013

Available online 27 November 2013

\section{Keywords:}

Sulfapyridine

Photodegradation

Transformation products

Toxicity

\begin{abstract}
A B S T R A C T
In this study, the photoinduced degradation of sulfapyridine (SPY) was investigated under simulated light irradiation $(\lambda>200 \mathrm{~nm})$. The effect of $\mathrm{pH}$ and main water constituents including nitrate ion, bicarbonate, dissolved organic matter (DOM) and iron(III) on the photodegradation was explored. SPY was effectively removed in aqueous solution at $\mathrm{pH} 8$ under UV-vis irradiation, with removal efficiency of $100 \%$ within $120 \mathrm{~min}$. DOM and iron(III) had retarding influence on the SPY removal, whereas nitrate ion and bicarbonate did not show any obvious effect. Under UV-vis irradiation, the formation of singlet oxygen $\left({ }^{1} \mathrm{O}_{2}\right)$ accelerated the SPY photodegradation and the contribution of indirect photolysis due to reaction with ${ }^{1} \mathrm{O}_{2}$ was up to $42 \%$. The transformation products of SPY were identified by HPLC-MS and the possible photoreaction pathways were proposed. It showed that photoinduced hydrolysis, photo-oxidation via ${ }^{1} \mathrm{O}_{2}$ and desulfonation were the main degradation ways for SPY decomposition. Toxicity assays by Vibrio fischeri proved that the transformation products were more toxic than the parent compound.
\end{abstract}

(c) 2013 Elsevier Ltd. All rights reserved.

\section{Introduction}

Pharmaceuticals and personal care products (PPCPs) have received increasing concern from both public and scientific communities (Homem and Santos, 2011). Antibiotics are a class of commonly used PPCPs used as human and veterinary medicine. Due to their pseudo-persistent nature and potential to cause antibiotic resistant bacteria and genes (Baran et al., 2006; Zhang et al., 2013; Guo et al., 2013), it is imperative to study the fate and transport of antibiotics and their impacts in the natural environment (Ge et al., 2009, 2010; Guo et al., 2013).

Sulfonamides (SAs) are a class of broad-spectrum synthetic antibiotics still widely used for the prevention and treatment of diseases and infections as well as animal growth promoters (Zhang et al., 2013; Guo et al., 2013). The excretion from human and animals has caused their ubiquitous detection in surface water with

\footnotetext{
* Corresponding author. Tel.: +86 10 84915237; fax: +86 1084926073.

E-mail address: zhangyuan@craes.org.cn (Y. Zhang).
}

relatively high concentrations (Lindsey et al., 2001; Xu et al. 2007). In surface waters photochemical degradation was reported as one of the major removal pathways for SAs (Khaleel et al., 2012; Boreen et al., 2005; Guerard et al., 2009; Kim and Tanaka, 2009). SAs usually contain five- or six-membered heterocyclic groups which make them easily absorb light and undergo direct photodegradation under UV-vis irradiation (Boreen et al., 2004; Trovó et al., 2009). Indirect photolysis under irradiation due to energy transfer or chemical reactions with transient reactive intermediates such as hydroxyl radicals $\cdot \mathrm{OH}$ and singlet oxygen ${ }^{1} \mathrm{O}_{2}$ can also significantly enhance the photochemical decay for SAs (Boreen et al., 2004; Prados-Joya et al., 2011). Many studies on the photochemical degradation of SAs such as sulfamethazine, sulfamethoxazole, sulfadimethoxine have been conducted (Boreen et al., 2005; Lam and Mabury, 2005; Accinelli et al., 2006; Baran et al., 2006; Guerard et al., 2009; Nasuhoglu et al., 2011). Although they have similar structures, the photochemical behaviors of SAs are different from one another (Boreen et al., 2004, 2005).

During photochemical processes, the presence of water constituents has a great impact on the photodegradation process. Nitrate 
in surface water can mediate the formation of $\cdot \mathrm{OH}$ and oxidize organic pollutants (Brezonik and Fulkerson-Brekken, 1998), however, this process has been reported to be of no help for the elimination of sulfonamides (Trovó et al., 2009). Dissolved organic matter (DOM) in nature water can promote the indirect photolysis by direct energy transference or by producing oxidants such as $\cdot \mathrm{OH}$, $\mathrm{HOO} / \mathrm{O}_{2}^{-},{ }^{1} \mathrm{O}_{2}$, and also can inhibit the indirect photolysis for scavenging reactive oxygen species (ROS) or competitive light absorption (Fisher et al., 2006; Ge et al., 2009; Guerard et al., 2009). Bicarbonate has been documented to affect the photodegradation of PPCPs for the yield of $\mathrm{CO}_{3}^{-}$due to reaction with $\mathrm{OH}$, which is reactive for the easily oxidized substrates via one-electron oxidation and also can inhibit the photodegradation process of many organic pollutants (Feng and Nansheng, 2000; Lam and Mabury, 2005). $\mathrm{Fe}(\mathrm{III})$ complexes are acknowledged to assist organic compounds photodecomposition through internal charge transfer under irradiation to produce $\mathrm{Fe}(\mathrm{II})$ and $\cdot \mathrm{OH}$, which can promote the photochemical reaction and act as a catalytic oxidant (Feng and Nansheng, 2000; Fisher et al., 2006; Tercero Espinoza et al., 2007). The influence of these important factors should not be overlooked when considering photochemical processes of antibiotics in water.

Sulfapyridine (SPY), a sulfonamide antibiotic, may enter food chain and provoke acute and chronic adverse effects in the environment (Göbel et al., 2005). The information on photodegradation of SPY involved in the pathway and mechanism is quite limited, despite its common occurrence.

In this study the photodegradation of SPY under UV-vis light irradiation, as well as the influence of $\mathrm{pH}$, nitrate ion, bicarbonate, DOM and iron(III) on the photodegradation was investigated. The intermediates/products were identified and a possible degradation pathway was proposed. To evaluate the phototoxicity risks, toxicity assay by Vibrio fischeri was conducted to monitor the toxicity evolvement of reaction solutions as well.

\section{Material and methods}

\subsection{Chemicals and materials}

Sulfapyridine (purity > 99\%) was purchased from Sigma Aldrich (St. Louis, MO, USA). Organic solvents including methanol, isopropanol (HPLC grade) were purchased from Tedia Company, Inc. Humic acid sodium salt (HA) was purchased from Aldrich. Other chemicals were of guaranteed grade and used as received, without further purification. Ultrapure water was purified with a MilliporeMilli Q system (Millipore, Milford, MA, USA).

\subsection{Photodegradation experiments}

A $300 \mathrm{~W}$ high-pressure mercury lamp surrounded with a watercooled quartz well was employed to simulate the UV-vis irradiation $(\lambda \geqslant 200 \mathrm{~nm})$. The emission spectrum of the lamp was measured with a monochromator (Acton, SP-300) (Fig. S1) and the absorption spectrum of the SPY at different $\mathrm{pH}$ values was measured by Varian Cary 100 Scan UV-Vis spectrophotometer (Fig. S2). The light intensities $(200-420 \mathrm{~nm})$ in the center of the reactive solution were $4.10 \mathrm{~mW} / \mathrm{cm}^{2}$.

Photodegradation experiment was conducted in an XPA-7 photochemical reactor (Nanjing Xujiang Machinery Factory, China). Fifty milliliters of aqueous solution were added into the quartz tubes which were positioned in the center of the reactor at a fixed distance. The $\mathrm{pH}$ values of the solution during the irradiation were kept constant by addition of $\mathrm{NaOH}$ or $\mathrm{HCl}$. The irradiance measured by a radiometer and potassium ferrioxalate actinometry showed that the photon flux was relatively constant $(<5 \%)$. With the light on, an aliquot of $2 \mathrm{~mL}$ reaction solution was gathered at given time intervals. Dark controls wrapped in aluminum foil were run simultaneously under the same condition. The effect of water constituents, including nitrate ion, bicarbonate ion, iron(III) ion and HA on the SPY photodegradation was performed by adding corresponding components into the reaction solution. $\mathrm{NaN}_{3}$ and isopropanol, which are quenchers for ${ }^{1} \mathrm{O}_{2}$ and ${ }^{\circ} \mathrm{OH}$ were used to assess the presence of ${ }^{1} \mathrm{O}_{2}$ and $\mathrm{OH}$. All experiments were performed in triplicates.

\subsection{Instrumental analysis and intermediates identification}

SPY was quantified by an Agilent 1100 high performance liquid chromatograph coupled with diode array detection (HPLC-DAD). The DAD signal was acquired between 200 and $300 \mathrm{~nm}$, and absorbance at $261 \mathrm{~nm}$ was adopted as the quantification wavelength for SPY. A C18 reverse phase column $(150 \mathrm{~mm} \times 2.1 \mathrm{~mm}, 5 \mu \mathrm{m}$, Agilent, USA) was used for the separation. The mobile phase was comprised of $30 \%$ methanol and $70 \%$ water with $0.1 \%$ formic acid, and the flow rate was kept at $1.0 \mathrm{~mL} \mathrm{~min}{ }^{-1}$.

To identify the SPY photochemical intermediates/products, $50 \mathrm{~mL}$ solution with initial SPY concentration of $10 \mathrm{mg} \mathrm{L}^{-1}$ at $\mathrm{pH}$ 8 was irradiated for $120 \mathrm{~min}$. Samples were collected from the reactor at $30 \mathrm{~min}, 60 \mathrm{~min}$ and $120 \mathrm{~min}$, respectively, and analyzed by liquid chromatography mass spectrometry (LC-MS). LC-MS analysis was carried out on a Thermo LCQ Advantages instrument (Quest LCQ Duo, USA) equipped with an electrospray ionization (ESI) source and operated in the positive electronspray ionization mode (ESI+) over a mass range of $50-500 \mathrm{~m} / \mathrm{z}$. The capillary voltage and cone voltage were set at $3.5 \mathrm{kV}$ and $25 \mathrm{~V}$, respectively. The desolvation temperature and source temperature were at $350{ }^{\circ} \mathrm{C}$ and $120^{\circ} \mathrm{C}$, respectively. An eclipse XDB-C18 column $(100 \mathrm{~mm} \times 2.1 \mathrm{~mm}, 1.8 \mu \mathrm{m}$, Agilent, USA) was utilized for the LC separation with a mobile phase of solution A (with $0.1 \%$ formic acid) and solution $B$ (acetonitrile) at a flow rate of $0.3 \mathrm{~mL} \mathrm{~min}^{-1}$. The column was maintained at $40{ }^{\circ} \mathrm{C}$ during sample analysis. The gradient program was as follows: $0-5 \mathrm{~min}$ : $90 \% \mathrm{~A}$; $5-7 \mathrm{~min}: 85 \%$ A; 7-11 min: $60 \%$ A; $11-15$ min: $10 \%$ A; $15-25$ min: $90 \%$ A. The system was re-equilibrated for $10 \mathrm{~min}$ between runs.

\subsection{Toxicity measurements}

The bioluminescence inhibition assay was conducted to monitor the toxicity of an unirradiated SPY solution and the toxicity variation during the SPY photodegradation. V. fischeri and Microtox Model 500 Toxicity Analyzer were selected as the luminescent bacteria and testing equipment. The initial SPY concentration was $10 \mathrm{mg} \mathrm{L}^{-1}$, the same as those in product identification studies. Freeze-dried bacteria, reconstitution solution, diluent $(2 \% \mathrm{NaCl})$ and an adjustment solution (non-toxic $22 \%$ sodium chloride) were obtained from Beijing Hamamatsu (Beijing, China). Samples were examined in quartz tube containing $2 \%$ sodium chloride in three dilutions. A toxic-free control experiment in three repeats was conducted only containing $2 \%$ sodium chloride. The luminescence was recorded after $15 \mathrm{~min}$ of incubation at $15{ }^{\circ} \mathrm{C}$. The percentage of luminescence inhibition was calculated according to the procedure described by Calza et al. (2010).

\section{Results and discussion}

\subsection{SPY photodegradation at varying $p H$}

Photodegradation curves of SPY in aqueous solution at different $\mathrm{pH}$ values were illustrated in Fig. 1. It indicated that photolysis played an important role in the removal of SPY in aqueous solution. 


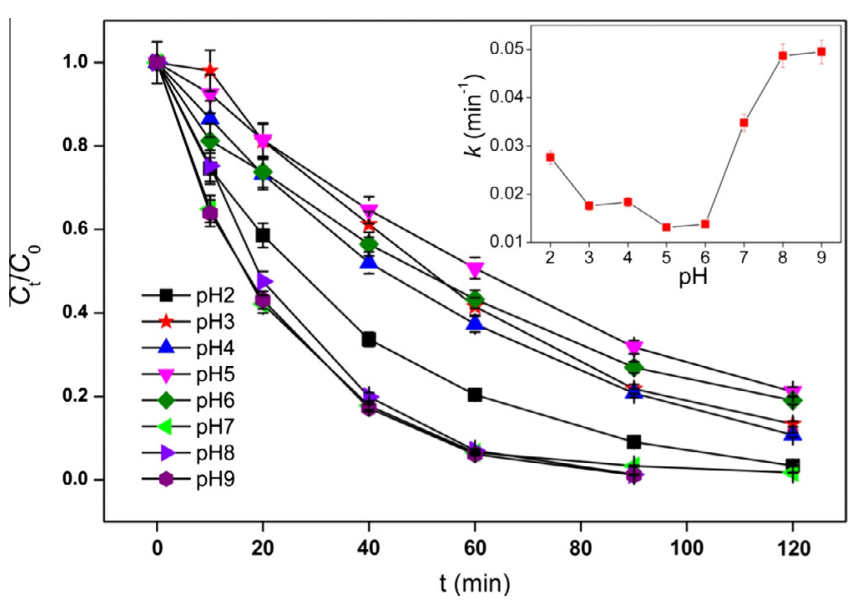

Fig. 1. The photodegradation of SPY at different $\mathrm{pH}$ and their corresponding rate constants. $[\mathrm{SPY}]_{0}=10 \mathrm{mg} \mathrm{L}^{-1}$.

Within $2 \mathrm{~h}$ of UV-vis irradiation, SPY at initial concentration of $10 \mathrm{mg} \mathrm{L}^{-1}$ was almost completely degraded under alkaline conditions.

Photochemical degradation of SPY in the solution could be well described by first-order reaction kinetics at various $\mathrm{pH}$ values. The degradation rate constant $k$ was obtained $\left(R^{2}\right.$ ranged from 0.9876 to 0.9988 ), as shown in inset of Fig. 1. In general, SPY degradation rates in alkaline conditions were greater than in acidic conditions. The highest $k$ value in water was found to be 0.049 and $0.050 \mathrm{~min}^{-1}$ at $\mathrm{pH} 8$ and $\mathrm{pH} 9$, respectively, apparently exceeding the maximal rate $\left(0.028 \mathrm{~min}^{-1}\right)$ in acidic solution at $\mathrm{pH} 2$. The half-lives $\left(t_{1 / 2}\right)$ calculated by equation $t_{1 / 2}=\ln 2 / k$ from $\mathrm{pH} 2$ to pH 9 were 25.0, 39.4, 37.7, 52.9, 50.2, 19.9, 14.2 and $14.0 \mathrm{~min}$, respectively. The difference of SPY degradation rates was likely related to the SPY speciation under different $\mathrm{pH}$ values. SPY has $\mathrm{p} K_{\mathrm{a} 1}$ and $\mathrm{p} K_{\mathrm{a} 2}$ values of 2.74 and 8.29 (Niu et al., 2007). Under acidic and alkaline environment different SPY speciation might affect the absorption of light wavelength (Fig. S2). In alkaline solution, substrate anion with a high electron density surrounding the ring system had more reactivity of photoreaction than its protonated or neutral species (Latch et al., 2005; Chen et al., 2010).

\subsection{Effect of water constituents on SPY photodegradation}

\subsubsection{Nitrate ion}

Nitrate ion existed with concentrations ranging from $10^{-5}$ to $10^{-3} \mathrm{M}$ in natural water (Mao et al., 2011). The effect of nitrate ion with concentrations from $0.5 \mathrm{mM}$ to $10 \mathrm{mM}$ was shown in Fig. 2a. Results indicated that increasing nitrate concentration did not significantly accelerate the removal of SPY in water. It is acknowledged that in nature waters nitrate is the primary source of hydroxyl radical $\mathrm{OH}$, and molecular probes like methanol and isopropanol are usually employed to determine $\mathrm{OH}$ (Zhou and Mopper, 1990; Brezonik and Fulkerson-Brekken, 1998; Ge et al., 2010). Experimental results by adding isopropanol to the solution revealed that ${ }^{\circ} \mathrm{OH}$ seemingly did not contribute to the SPY degradation under the conditions in this study, since there was no significant alternation for improving the photodegradation of SPY (Fig. 2a).

\subsubsection{Bicarbonate ion}

Bicarbonate is another bounteous anion in nature water (Tercero Espinoza et al., 2007; Mao et al., 2011). Prior studies have
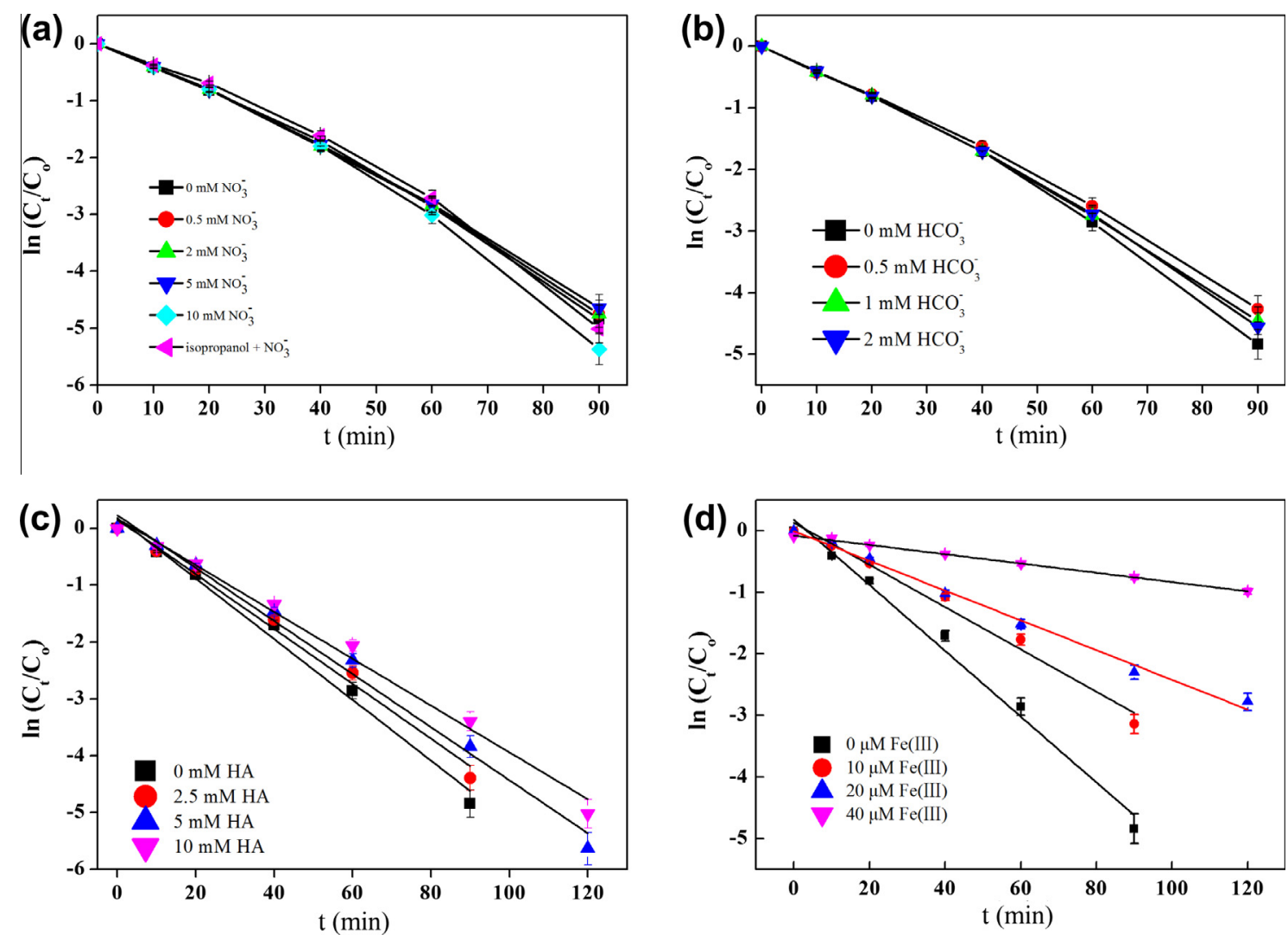

Fig. 2. Effect of nitrate (a), bicarbonate (b), HA (c) and Fe(III) (d) on the photolysis of SPY in aqueous solution. $[S P Y]_{0}=10 \mathrm{mg} \mathrm{L}^{-1}$, $\mathrm{pH}=8$. 


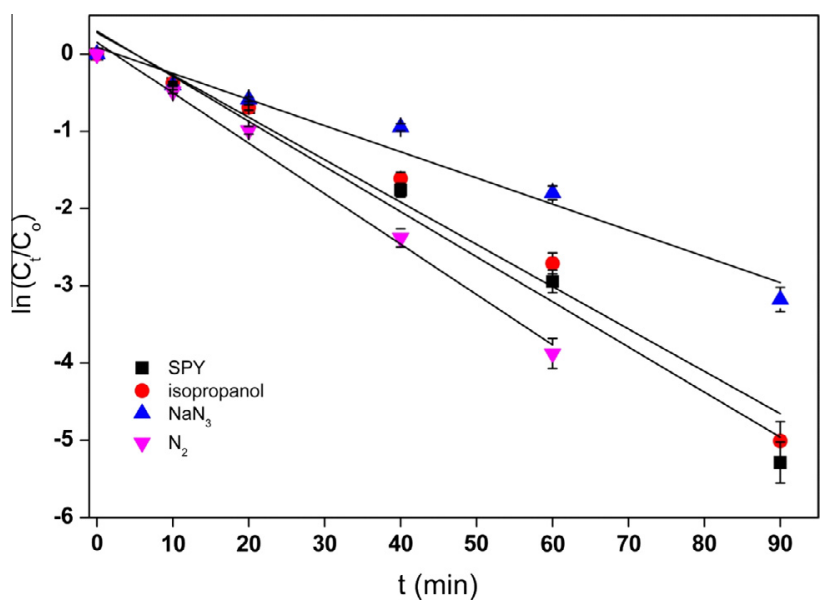

Fig. 3. Effect of $\mathrm{NaN}_{3}(8 \mathrm{mM})$, isopropanol $(10 \mathrm{mM})$ and $\mathrm{N}_{2}$ on photodegradation of SPY in water. $[\mathrm{SPY}]_{0}=10 \mathrm{mg} \mathrm{L}^{-1}, \mathrm{pH}=8$.

found that bicarbonate is a well-known radical scavenger which can cause $\sim 10 \%$ of the $\mathrm{OH}$ scavenging (Brezonik and FulkersonBrekken, 1998). The reaction between $\mathrm{OH}$ and either carbonate or bicarbonate ion is conductive to the formation of carbonate radicals $\mathrm{CO}_{3}^{-}$which is more selective and less reactive than ${ }^{\circ} \mathrm{OH}$, and can easily result in the degradation of easily oxidized organic substances (Huang and Mabury, 2000; Mazellier et al., 2007).

The influence of biocarbonate on SPY photodegradation was illustrated in Fig. 2b. Similar to nitrate, the presence of bicarbonate did not significantly affect the SPY degradation. Although the radical $\mathrm{CO}_{3}^{-}$in natural waters contains a higher steady-state level than ' $\mathrm{OH}$ due to its lower reactivity (Vione et al., 2009), neither $\mathrm{CO}_{3}^{-}$nor 'OH played an important role in the SPY photochemical degradation under UV-vis light irradiation in alkaline conditions.

\subsubsection{Natural organic matter (DOM)}

Dissolved organic matter is a major form in which organic carbon is present in surface or ground water (Fisher et al., 2006). DOM plays an important role in light-induced photochemical processes in natural waters. On the one hand, it can inhibit the photochemical degradation as a consequence of the competitive light absorption or $\mathrm{OH}$ scavenging; on the other hand, it may promote the photochemical degradation by producing oxidants such as $\mathrm{OH}$ and HOO $/ \mathrm{O}_{2}^{-}$, (Doll and Frimmel, 2005; Fisher et al., 2006). The effect of humic acid (HA, representing DOM in this study) on the SPY photodegradation was shown in Fig. 2c. In the presence of HA, the SPY photodegradation was inhibited.

As shown in Fig. S3, HA absorbs UV-vis from 200 to $700 \mathrm{~nm}$. The inhibition effect of HA was probably due to the competitive absorption of short-wavelength photons under UV-vis irradiation $(\lambda>200 \mathrm{~nm})$ since HA could absorb more UV than visible light (Fig. S3) and $\cdot \mathrm{OH}$ was of no help to SPY photodegradation. Although HA could also enhance the photodegradation as a photosensitizer (Hassett, 2006; Vione et al., 2006; Zhan et al., 2006), the result of this experiment indicated that photosensitization might be secondary to the SPY degradation. This was corresponded with previous studies that HA could bring about light attenuation (Dimou et al., 2004, 2005; Ge et al., 2009).

\subsubsection{The effect of $\mathrm{Fe}(\mathrm{III})$}

Iron is one of the most abundant elements in natural waters, including many classes of iron metal, compounds, and mixtures (Feng and Nansheng, 2000). To explore the role of Fe(III) in SPY photochemical degradation, $\mathrm{FeCl}_{3}$ with concentrations from $10 \mu \mathrm{M}$ to $40 \mu \mathrm{M}$ was added into SPY aqueous solution. Fig. $2 \mathrm{~d}$ showed that the existence of $\mathrm{Fe}(\mathrm{III})$ inhibited the SPY photodegradation.

$\mathrm{Fe}(\mathrm{III})$ was conducive to the photodegradation of antibiotics such as sulfadimethoxine (Guerard et al., 2009), and a positive role of $\mathrm{Fe}(\mathrm{III})$ in the photodegradation of SPY was expected. However, experimental result in this study showed a reverse trend. The experiment was conducted at $\mathrm{pH} 8$. At the most acidic condition, $\mathrm{Fe}(\mathrm{III})$ is mainly in the dissolved form $\left(\mathrm{Fe}^{3+}, \mathrm{FeOH}^{2+}\right.$, and $\mathrm{Fe}_{2}(\mathrm{OH})_{2}^{4+}$ ), especially $\mathrm{FeOH}^{2+}$ could be photoactive to the decay of organic compounds due to the photoformed $\mathrm{OH}$. With $\mathrm{pH}$ increases, the main form of iron species are dimeric and oligomeric $\mathrm{Fe}(\mathrm{III})$ compounds and colloids, leading to less dissolved Fe(III) in solution and ROS scavenged (Chiron et al., 2006). The competitive photoabsorption by $\mathrm{Fe}(\mathrm{III})$ also should not be overlooked. The above two factors may be the reasons for the inhibition effect of $\mathrm{Fe}(\mathrm{III})$ on the SPY photodegradation.

\subsection{Photodegradation mechanisms and intermediates/products identification}

Fig. 3 illustrated that the addition of $\mathrm{NaN}_{3}$ into the reaction solution had an obvious inhibiting effect on the SPY photodegradation, while isopropanol did not affect the degradation rate. Since $\mathrm{NaN}_{3}$ is the scavenger of ${ }^{1} \mathrm{O}_{2}$ and isopropanol is the scavenger of 'OH or $\mathrm{O}_{2}^{--}$(Chen et al., 2008; Guo et al., 2013; Xu et al., 2013) the result indicated that ${ }^{1} \mathrm{O}_{2}$ rather than $\mathrm{OH}$ or $\mathrm{O}_{2}^{--}$was generated and played roles in SPY photodegradation. The photodegradation of SPY in $\mathrm{O}_{2}$ free solution by purging nitrogen into the solution was accelerated (Fig. 3), which was likely because dissolved oxygen (DO) in the solution could dampen photochemical reaction through quenching the molecules from excited triplet state to unexcited state (Shirayama et al., 2001). Result also showed that increasing initial aqueous concentrations reduced SPY photodegradation rates (Fig. S4), which was consistent with the results by other researchers (Gan et al., 1996; Fogg et al., 2003).

Seven photochemical reaction intermediates/products were identified, with relevant information including total ion chromatograms and mass spectra provided in Figs. S5 and S6. SPY could undergo three reactions on basis of the product identifications: photoinduced hydrolysis, photo-oxidation and desulfonation, which are also common reaction types for the photodecomposition of other compounds (Ge et al., 2009; Trovó et al., 2009). The photooxidation reaction mediated via ${ }^{1} \mathrm{O}_{2}$ generated product $\mathrm{VI}$, which was transformed into VII through reduction process. Product IV came from reductive desulfonation, and further underwent photohydrolysis at different nitrogen atoms in the molecules IV, generating the isomers V. The direct photolysis of SPY could result in III, II and I. The photochemical degradation pathways were proposed and illustrated in Fig. 4.

\subsection{Toxicity evolvement}

$V$. fischeri luminescent bacteria was widely employed to evaluate the ecotoxicological effect in aquatic ecosystem, and displayed good correlations with other bioassays (Calza et al., 2010). The toxicity evolvement of SPY at different irradiation time was plotted in Fig. 5. The luminescence inhibition rate of the parent SPY $(0 \mathrm{~h}$ of irradiation) to $V$. fischeri was $12.5 \%$, and with the irradiation time went on, the toxicity first slightly decreased to $5 \%$ at $10 \mathrm{~min}$, then increased all the way up to the highest of $50.6 \%$ at $120 \mathrm{~min}$. This result indicated that the photochemical degradation of SPY generated intermediates/products much more toxic than the parent compound. However, it is noted that the actual levels of SPY in most natural water bodies are lower than the concentrations adopted in this study, and the phototoxicities could hardly exhibit in real environment. 


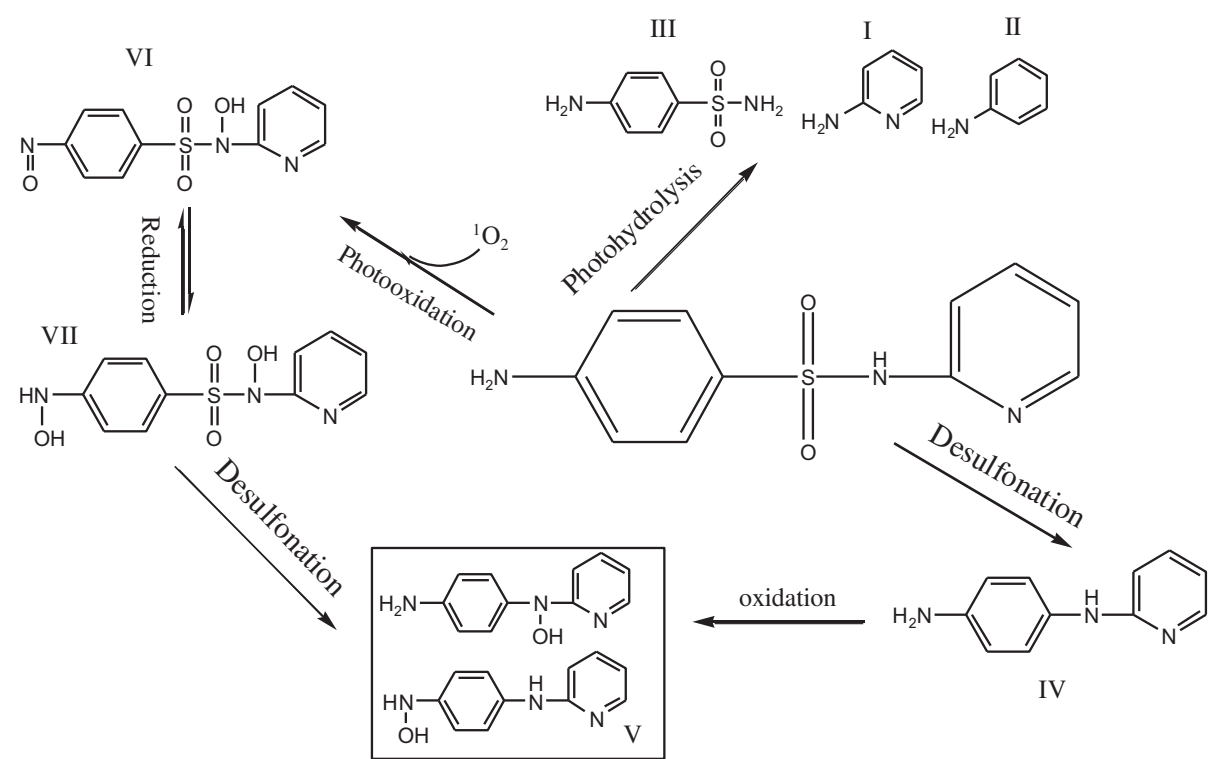

Fig. 4. Proposed transformation pathways for SPY photodegradation of in water. $[S P Y]_{0}=10 \mathrm{mg} \mathrm{L}^{-1}, \mathrm{pH}=8$.

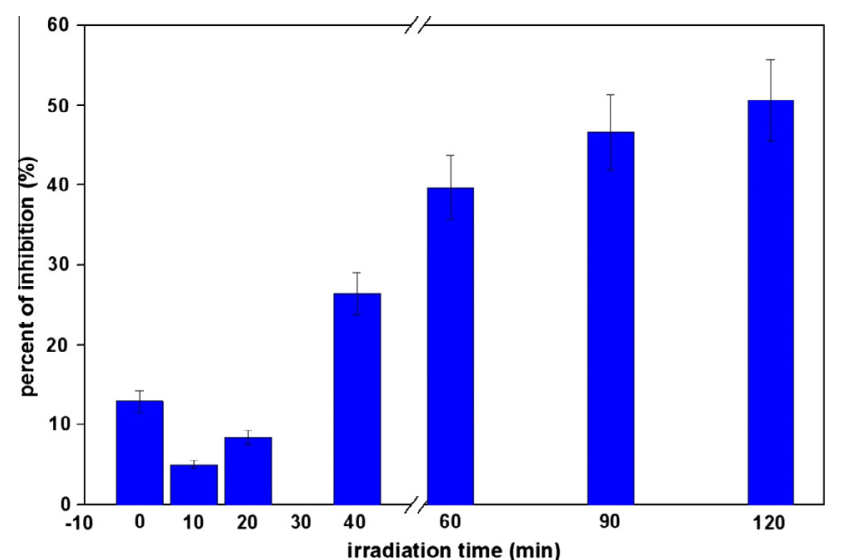

Fig. 5. Inhibition of photobacteria $V$. fischeri as a function of irradiation time for SPY. $[\mathrm{SPY}]_{0}=10 \mathrm{mg} \mathrm{L}^{-1}, \mathrm{pH}=8$.

\section{Conclusions}

Investigation of the effect of ubiquitous water constituents on the SPY photodegradation, and exploration of the mechanism of SPY photodegradation under UV-vis light irradiation are of great importance to assess its environmental fate and risks. Results from this study showed that the SPY removal by photodegradation was more effective in alkaline environment than in acidic environment. The photolysis of SPY was inhibited in the presence of HA and $\mathrm{Fe}(\mathrm{III})$, while nitrate and bicarbonate did not play important roles. The reactive species quenching results revealed that the direct photolysis and photosensitized oxidation via ${ }^{1} \mathrm{O}_{2}$ were the main photochemical reaction processes. LC-MS analysis identified seven reaction intermediates/products, which were much more toxic toward the photobacteria $V$. fischeri than SPY itself.

\section{Acknowledgement}

This work was supported by the National Natural Science Foundation of China (51178438 and 51208482).

\section{Appendix A. Supplementary material}

Supplementary data associated with this article can be found, in the online version, at http://dx.doi.org/10.1016/j.chemosphere. 2013.10.069.

\section{References}

Accinelli, C., Hashim, M., Epifani, R., Schneider, R.J., Vicari, A., 2006. Effects of the antimicrobial agent sulfamethazine on metolachlor persistence and sorption in soil. Chemosphere 63, 1539-1545.

Baran, W., Sochacka, J., Wardas, W., 2006. Toxicity and biodegradability of sulfonamides and products of their photocatalytic degradation in aqueous solutions. Chemosphere 65, 1295-1299.

Boreen, A.L., Arnold, W.A., McNeill, K., 2004. Photochemical fate of sulfa drugs in the aquatic environment: sulfa drugs containing five-membered heterocyclic groups. Environ. Sci. Technol. 38, 3933-3940.

Boreen, A.L., Arnold, W.A., McNeill, K., 2005. Triplet-sensitized photodegradation of sulfa drugs containing six-membered heterocyclic groups: identification of an $\mathrm{SO}_{2}$ extrusion photoproduct. Environ. Sci. Technol. 39, 3630-3638.

Brezonik, P.L., Fulkerson-Brekken, J., 1998. Nitrate-induced photolysis in natural waters: controls on concentrations of hydroxyl radical photo-intermediates by natural scavenging agents. Environ. Sci. Technol. 32, 3004-3010.

Calza, P., Marchisio, S., Medana, C., Baiocchi, C., 2010. Fate of antibacterial spiramycin in river waters. Anal. Bioanal. Chem. 396, 1539-1550.

Chen, Y., Hu, C., Qu, J., Yang, M., 2008. Photodegradation of tetracycline and formation of reactive oxygen species in aqueous tetracycline solution under simulated sunlight irradiation. J. Photochem. Photobiol. A 197, 81-87.

Chen, Z., Cao, G., Song, Q., 2010. Photo-polymerization of triclosan in aqueous solution induced by ultraviolet radiation. Environ. Chem. Lett. 8, 33-37.

Chiron, S., Minero, C., Vione, D., 2006. Photodegradation processes of the antiepileptic drug carbamazepine, relevant to estuarine waters. Environ. Sci. Technol. 40, 5977-5983.

Dimou, A.D., Sakkas, V.A., Albanis, T.A., 2004. Trifluralin photolysis in natural waters and under the presence of isolated organic matter and nitrate ions: kinetics and photoproduct analysis. J. Photochem. Photobiol. A 163, 473-480.

Dimou, A.D., Sakkas, V.A., Albanis, T.A., 2005. Metolachlor photodegradation study in aqueous media under natural and simulated solar irradiation. J. Agric. Food Chem. 53, 694-701.

Doll, T.E., Frimmel, F.H., 2005. Photocatalytic degradation of carbamazepine, clofibric acid and iomeprol with P25 and Hombikat UV100 in the presence of natural organic matter (NOM) and other organic water constituents. Water Res. 39, 403-411.

Feng, W., Nansheng, D., 2000. Photochemistry of hydrolytic iron(III) species and photoinduced degradation of organic compounds. A minireview. Chemosphere 41, 1137-1147.

Fisher, J.M., Reese, J.G., Pellechia, P.J., Moeller, P.L., Ferry, J.L., 2006. Role of Fe(III), phosphate, dissolved organic matter, and nitrate during the photodegradation of domoic acid in the marine environment. Environ. Sci. Technol. 40, 2200 2205.

Fogg, P., Boxall, A.B.A., Walker, A., 2003. Degradation of pesticides in biobeds: the effect of concentration and pesticide mixtures. J. Agric. Food Chem. 51, 5344 5349. 
Gan, J., Becker, R.L., Koskinen, W.C., Buhler, D.D., 1996. Degradation of atrazine in two soils as a function of concentration. J. Environ. Qual. 25, 1064-1072.

Ge, L., Chen, J., Qiao, X., Lin, J., Cai, X., 2009. Light-source-dependent effects of main water constituents on photodegradation of phenicol antibiotics: mechanism and kinetics. Environ. Sci. Technol. 43, 3101-3107.

Ge, L., Chen, J., Wei, X., Zhang, S., Qiao, X., Cai, X., Xie, Q., 2010. Aquatic photochemistry of fluoroquinolone antibiotics: kinetics, pathways, and multivariate effects of main water constituents. Environ. Sci. Technol. 44, 2400-2405.

Göbel, A., Thomsen, A., McArdell, C.S., Joss, A., Giger, W., 2005. Occurrence and sorption behavior of sulfonamides, macrolides, and trimethoprim in activated sludge treatment. Environ. Sci. Technol. 39, 3981-3989.

Guerard, J.J., Chin, Y.-P., Mash, H., Hadad, C.M., 2009. Photochemical fate of sulfadimethoxine in aquaculture waters. Environ. Sci. Technol. 43, 8587-8592.

Guo, C., Xu, J., Wang, S., Zhang, Y., He, Y., Li, X., 2013. Photodegradation of sulfamethazine in an aqueous solution by a bismuth molybdate photocatalyst. Catal. Sci. Technol. 3, 1603-1611.

Hassett, J.P., 2006. Dissolved natural organic matter as a microreactor. Science 311 $1723-1724$.

Homem, V., Santos, L., 2011. Degradation and removal methods of antibiotics from aqueous matrices - a review. J. Environ. Manage. 92, 2304-2347.

Huang, J., Mabury, S.A., 2000. Steady-state concentrations of carbonate radicals in field waters. Environ. Toxicol. Chem. 19, 2181-2188.

Khaleel, N.D.H., Mahmoud, W.M.M., Hadad, G.M., Abdel-Salam, R.A., Kümmerer, K., 2012. Photolysis of sulfamethoxypyridazine in various aqueous media: aerobic biodegradation and identification of photoproducts by LC-UV-MS/MS. J. Hazard. Mater. 244-245, 654-661.

Kim, I., Tanaka, H., 2009. Photodegradation characteristics of PPCPs in water with UV treatment. Environ. Int. 35, 793-802.

Lam, M.W., Mabury, S.A., 2005. Photodegradation of the pharmaceuticals atorvastatin, carbamazepine, levofloxacin, and sulfamethoxazole in natural waters. Aquat. Sci. 67, 177-188.

Latch, D.E., Packer, J.L., Stender, B.L., VanOverbeke, J., Arnold, W.A., McNeill, K., 2005 Aqueous photochemistry of triclosan: formation of 2,4-dichlorophenol, 2,8 dichlorodibenzo-p-dioxin, and oligomerization products. Environ. Toxicol. Chem. 24, 517-525.

Lindsey, M.E., Meyer, M., Thurman, E.M., 2001. Analysis of trace levels of sulfonamide and tetracycline antimicrobials in groundwater and surface water using solid-phase extraction and liquid chromatography/mass spectrometry. Anal. Chem. 73, 4640-4646.

Mao, L., Meng, C., Zeng, C., Ji, Y., Yang, X., Gao, S., 2011. The effect of nitrate bicarbonate and natural organic matter on the degradation of sunscreen agent p-aminobenzoic acid by simulated solar irradiation. Sci. Total. Environ. 409, 5376-5381.
Mazellier, P., Busset, C., Delmont, A., De Laat, J., 2007. A comparison of fenuron degradation by hydroxyl and carbonate radicals in aqueous solution. Water Res. 41, 4585-4594.

Nasuhoglu, D., Yargeau, V., Berk, D., 2011. Photo-removal of sulfamethoxazole (SMX) by photolytic and photocatalytic processes in a batch reactor under UV-C radiation (lambdamax $=254 \mathrm{~nm}$ ). J. Hazard. Mater. 186, 67-75.

Niu, H., Cai, Y., Shi, Y., Wei, F., Liu, J., Mou, S., Jiang, G., 2007. Evaluation of carbon nanotubes as a solid-phase extraction adsorbent for the extraction of cephalosporins antibiotics, sulfonamides and phenolic compounds from aqueous solution. Anal. Chim. Acta 594, 81-92.

Prados-Joya, G., Sánchez-Polo, M., Rivera-Utrilla, J., Ferro-garcía, M., 2011. Photodegradation of the antibiotics nitroimidazoles in aqueous solution by ultraviolet radiation. Water Res. 45, 393-403.

Shirayama, H., Tohezo, Y., Taguchi, S., 2001. Photodegradation of chlorinated hydrocarbons in the presence and absence of dissolved oxygen in water. Water Res. 35, 1941-1950.

Tercero Espinoza, L.A., Neamţu, M., Frimmel, F.H., 2007. The effect of nitrate, Fe(III) and bicarbonate on the degradation of bisphenol A by simulated solar UVirradiation. Water Res. 41, 4479-4487.

Trovó, A.G., Nogueira, R.F.P., Agüera, A., Sirtori, C., Fernández-Alba, A.R., 2009. Photodegradation of sulfamethoxazole in various aqueous media: persistence, toxicity and photoproducts assessment. Chemosphere 77, 1292-1298.

Vione, D., Falletti, G., Maurino, V., Minero, C., Pelizzetti, E., Malandrino, M., Ajassa, R., Olariu, R.I., Arsene, C., 2006. Sources and sinks of hydroxyl radicals upon irradiation of natural water samples. Environ. Sci. Technol. 40, 3775-3781.

Vione, D., Khanra, S., Man, S.C., Maddigapu, P.R., Das, R., Arsene, C., Olariu, R.-I. Maurino, V., Minero, C., 2009. Inhibition vs. enhancement of the nitrate-induced phototransformation of organic substrates by the $\mathrm{OH}$ scavengers bicarbonate and carbonate. Water Res. 43, 4718-4728.

Xu, W.H., Zhang, G., Zou, S.C., Li, X.D., Liu, Y.C., 2007. Determination of selected antibiotics in the Victoria Harbour and the Pearl River, South China using highperformance liquid chromatography-electrospray ionization tandem mass spectrometry. Environ. Pollut. 145, 672-679.

Xu, J., Li, L., Guo, C., Zhang, Y., Wang, S., 2013. Removal of benzotriazole from solution by BiOBr photocatalysis under simulated solar irradiation. Chem. Eng. J. 221, 230-237.

Zhan, M., Yang, X., Xian, Q., Kong, L., 2006. Photosensitized degradation of bisphenol A involving reactive oxygen species in the presence of humic substances. Chemosphere 63, 378-386.

Zhang, Y., Xu, J., Zhong, Z., Guo, C., Li, L., He, Y., Fan, W., Chen, Y., 2013. Degradation of sulfonamides antibiotics in lake water and sediment. Environ. Sci. Pollut. R 20, 2372-2380.

Zhou, X., Mopper, K., 1990. Determination of photochemically produced hydroxyl radicals in seawater and freshwater. Mar. Chem. 30, 71-88. 